\title{
Interactive Lecturing by Integrating Mobile Devices and Micro-blogging in Higher Education
}

\author{
Martin Ebner \\ Social Learning / Computer and Information Services, Graz University of Technology, Austria
}

Following the recent advances in both technology and social interaction, implementation of interactivity to large lecture rooms presents itself as a promising new methodology to improve the learning and teaching process in academia. Namely, based on the underlying ideas of Web 2.0, learners should be able to collect and share online resources during a lecture, additional communication channels such as discussion forums, chat and microblogging helping to achieve interactivity on traditional face-to-face teaching. Building on such premises, first experiences have been acquired by the use of mobile devices and instant messaging in enhancing the learning and teaching behavior, with the help of a university wide available Learning Management System (LMS), which has accordingly been adapted and extended to the specific needs of supporting interactivity through mobile devices. The LMS is intended to use common and existing software and hardware (devices of the learners). The goal of the above research is to find out the potentials of interactivity in order to enhance students' engagement in traditional face-to-face teaching in Higher Education.

The paper describes the outcomes of the first experiments in implementing interactivity in Higher Education in such a framework within the Graz University of Technology (TU Graz) and comments on the methodology applied. The experiments, which have been performed during lecturing within the course "Social Aspects of Information Technology" at the BSc level, attended by about 200 students, have shown that such kind of interactivity has a positive effect on the learners' engagement.

Keywords: e-Learning, higher education, interactive lecture, Web 2.0, e-Learning 2.0
"The revolution of computers was not their evolution, but their connections to a large network"

Prof. Hermann Maurer, Austria

\section{Introduction}

Tim O'Reilly coined the term Web 2.0 (O'Reilly, 2005) for the first time and described the next stage of the WorldWideWeb, which has been already formulated by Tim Berners-Lee in 1989 (Berners-Lee, 1989): A network that anyone from anywhere in the world can contribute to.

Nowadays web applications like Wikipedia, YouTube, Flickr etc. seem to have become part of our daily life (Maurer \& Schinagl, 2006) (Richardson 2006) and help us to exchange, share and contribute to a worldwide global community (Korica et al., 2006). By using them for teaching and learning purposes Stephen Downes named it e-Learning 2.0 (Downes, 2005). Especially Wikis, (Augar et al., 2005) (Caddick, 2006) Weblogs (Luca \& McLoughlin, 2005) (Farmer \& Bartlett-Bragg, 2005) and Podcasts (Evans, 2007) (Towned, 2005) have turned out to be successful possibilities to enhance Higher Education lecturing widely spread (Raitman et al., 2005) (Ebner, 2007a). Even few attempts of micro-blogging for learning processes (Ebner \& Schiefner, 2008a) display that Web 2.0 approaches in the educational field are nearly endless.

But there is one amazing phenomenon: all these technologies are not new at all, but have not 
been used yet. From a technical point of view, these concepts and possibilities are matters of the "past", of the very first beginning of WorldWideWeb. So it must be asked: why does this change happen now? Within the teaching and learning environment the term "Social Learning" often occurs according to the aspect that many people share, collect and discuss worldwide over different websites and applications. Within a few years, social facilitations (Conte \& Paolucci, 2001) have helped to support an amazing change in the "use of the web".

It seems that there are crucial factors (Ebner et. Al, 2007b) being responsible for this "social revolution" (Downes, 2005) of the WorldWideWeb:

- Accessibility: Nowadays broadband access to the Internet is provided to anyone at least in all West European countries. Furthermore, it is affordable. According to different statistical data ${ }^{12}$ nearly the whole population of the European Union has access to the WorldWideWeb. It can be pointed out, that not only the precondition - access to the Internet - is fulfilled, even more, the connection speed is as high as it is necessary for working and dealing with it.

- Devices: Social software gets better the more people use it (O'Reilly, 2005) and gets better the more people get in touch with other (social connections). This argument leads to a request of an improvement of the existing infrastructure. WLAN, GPRS, UMTS as well as new generations of mobile devices (iPhone, Nokia N95, ...) improve this situation. Pervasive computing is an extremely emerging area by disseminating technologies for our daily routines, as Mark Weiser already pronounced in 1991 (Weiser, 1991).

- Usability: The last crucial factor is the increasing "ease of use" (Nielsen, 2003). Contributing to the Web needs no special skills as HTML-knowledge or even more Webprogramming knowledge anymore. Writing, sharing and collecting have become as easy as dealing with common desktop applications. Combining different resources within one webpage, called MashUp (Kulathormamaiyer \& Maurer, 2007), is a usual thing of Web 2.0 and helps to personalize digital content. Personal learning environments are getting popular more and more; asking how learners are dealing with content in a specific context (Schaffert \& Hilzensauer, 2008).

It can be summarized that hard- and softwares make it possible to get the users more and more involved to the "next-generation" Internet, called Web 2.0. Instead of consuming static Web-pages, learners of today become active by sharing their thoughts and discussing using different technologies on the Web. According to different studies ${ }^{3}$ about the competencies in relation to dealing with media, the use of Internet and different Web 2.0 applications are growing rapidly, especially amongst younger generations. Buzzwords like Digital Natives (Prensky, 2001), Net-Generation (Tapscott, 1997), Generation@(Opaschowski) and some more try to describe the impact on our youth because of changing and emerging digital technologies.

\section{Blogging and Micro-blogging - New Pedagogical Possibilities?}

As mentioned in previous chapter, Web 2.0 technologies are influencing Higher Education considerably. Maybe the most famous part of this movement is the use of Weblogs or simply Blogs. Looking for a definition about this phenomenon, Walker (Walker, 2007) and Schmidt (Schmidt et al, 2005) described it best: "A Weblog is a frequently updated website consisting of data entries arranged in a reverse chronological order".

Hence, it can be shown (Ebner and Taraghi, 2008c) that Weblogs replace traditional HTMLpages due to the fact of actuality ("frequently updated") and personality ("data entries" of users). Even more, by integrating Weblogs into the daily working routine of researchers the tool can turn into a new form of digital memory by strengthening three crucial factors: individuality, collectivity and community (Schiefner and Ebner, 2008). Furthermore, several examples point out how Weblogs can be used for different didactical scenarios: Karger \& Quan (Karger \& Quan, 2005) reported that the concept of decentralization, per-user publication and user centered information helps to improve lectures. Luca \& McLoughlin (Luca \& McLoughlin, 2005) presented that tracking and checking running processes of oneself and anyone from the learner group is of high relevance. 
Finally, Weblogs also support community building by becoming part of a wide-communication network (Peschke \& Lübecke, 2005).

Based on the track record of Weblogs, so-called Micro-blogs started in 2006 to provide a more flexible possibility of communication. Instead of writing essays, micro-blogging is about posting updates, ideas or simple notifications (McFedries, 2007). Java (Java et al, 2007) claimed three different kinds of Micro-blogs: information sharing, information seeking and friendship relationship. Especially for learning activities, the new form of communication becomes valuable as well as the support of mobility (Ebner \& Schiefner, 2007). Huberman et al. (Huberman et al, 2009) pointed out the social networking aspect and strengthening of the communication process through microblogging platforms. It can be summarized that there are two big advantages by using Microblogs: fast and mobile communication. Bearing his arguments in mind, the research group concentrated on the integration of micro-blogging possibilities into the existing learning management system.

\section{Research Issues in Interactive Lecturing}

\subsection{Teaching in Huge Classrooms}

On the one hand there are learners dealing with new technologies in their daily life, on the other hand there are educational institutions working in very traditional settings.

Most lectures at universities in West-European Countries are realized through face-to-face teaching in large lecturing rooms, using blackboard and PowerPoint presentations. Lecturers are presenting new information to a mass of learners, disregarding their individual learning processes and teachers, as well as students, reduce classroom-interactivity to the possibility of asking questions. To improve the situation the worldwide education research community has a long tradition of learner-lecturer interaction in huge classes (Bligh, 1971) (Gleason, 1986). Anderson (Anderson et al, 2003) mentioned that there are mainly three big problems:

- Feedback Lag: Missing feedback of the learners during the lecture
- Student Apprehension: Fear to ask or talk during the lecture because of the huge class

- Single Speaker Paradigm: The only-onespeaker syndrome (learner-lecturer) leads to less participation

But learning is a social and active process, which proceeds by and through conversation (Motschnig-Pitrik \& Holzinger, 2002) (Holzinger et al, 2008) and interaction (Preece et al, 2002). So there is a necessity to improve the directed interactivity by encouraging the communication between lecturers and learners.

Furthermore, an essential problem is the continuous attention required by the students over a long time period (at least 45-90 minutes). Bearing in mind that according to Smith (Smith, 2001) the attention span is only about 20 minutes, the setting of traditional information presentation should be rethought.

This research described in this paper aims to show the way to enhance traditional lecturing by considering the following factors:

- Interactivity: Improve the interaction between students-lecturers during a face-toface lecture

- Community: Bring the social community aspect into the lecture room - sharing, collecting and discussing using the possibilities of Web 2.0.

- Infrastructure: Use of common software (existing system) and supporting all devices of the learners (mobile phones as well as laptops)

We like to address the following research question: How can existing software be enhanced to bring "Learners 2.0" ideologies to a traditional and huge lecture room?

\subsection{Existing Systems for Enhancing Classroom Interactivity}

According to the research question addressed above and after studying existing literature (see below) different attempts have been made up to this moment, which include, for example, Classtalk $^{4}$, ClassInHand ${ }^{5}$, ConcertStudeo ${ }^{6}$, CFS (Anderson et al, 2003) and ActiveClass (Ratto et al, 2003). These systems can be stated as the very first ones, which try to enhance interaction between teachers and students. Almost 
all of these systems focus on a specific interaction issue (feedback or quizzes only) or need a special kind of device (PDAs). Table 1 shows an overview of existing systems.

Other systems are either dealing with streaming possibilities and synchronous playbacks as, for example, a tool called AuthoringOnTheFly (Datta \& Ottmann, 2001) or are new specially programmed tools to manage the challenge of classroom interaction (Scheele et al, 2005). A very new and innovative project dealing with Web 2.0 experiences for the first time has been launched at Vienna University of Technology (Purgarthofer \& Reinhaler, 2008). With the help of push-technology (changes are automatically displayed on client screens too) students can follow the current presentation and share their notes as well as comment them in interaction with their colleagues during the lecture.

Bearing in mind these experiences and according to the crucial factors we strongly emphasize (see also Table 1) that, beyond the support of interactivity, existing infrastructure should be enhanced. Learners should be able to use their common learning environment with their common devices during the "interactive-lecturing" too.

\section{TU Graz TeachCenter - an Interactive Learning Management System}

At Graz University of Technology the learning management system in use is called TU GrazTeachCenter (TUGTC). Close to 230 courses have been offered on TUGTC to the students of
TU Graz by summer semester 2008. TUGTC is based on a software called WBT-Master that was developed at the Institute of Information Systems and Computer Media (IICM) (Helic et al, 2004). Within this system, all relevant learning materials, as well as communication tools, quizzes, file exchanges and some more different approaches are offered to enhance traditional teaching with new media. By using RSS technology and web services, exchange with Web 2.0 technologies is possible as well.

Furthermore, a special feature called eBook (Huber et al, 2008), allows combining several HTML-Pages to one structured online resource with chapters and tables of contents. Users are able to search, discuss the content or even annotate it (Dietinger \& Maurer, 1998) by simple marking the specific text passage online. Annotations are displayed in two different ways directly at the place of label or at the bottom of the page, either as direct annotation or as a kind of footnote. Of course, it is possible to comment or answer annotations if they are made public to others.

Figure 1 shows a typical page of an eBook within the learning management system TUGTC. The navigation pane is displayed on the left-hand side, while all the advanced features are displayed on the top of the screen. Communication within an eBook is possible through usual features like discussion forum (asynchronous) and chat (synchronous). Within this environment it is possible to provide a fully navigable HTML-structure simply by uploading different pages and defining the relationships. From a historical point of view, the main

\begin{tabular}{|l|l|l|l|}
\hline System & Interaction type (Student - lecturer) & Used devices & Environment \\
\hline \hline Classtalk & $\begin{array}{l}\text { Lecturer is able to force questions to } \\
\text { students' devices }\end{array}$ & PDA & Stand alone \\
\hline ClassInHand & $\begin{array}{l}\text { Presentation control application; quiz } \\
\text { feature }\end{array}$ & PDA & Stand alone \\
\hline ConcertStudeo & $\begin{array}{l}\text { Multiple choice quizzes, queries, brain- } \\
\text { storming sessions }\end{array}$ & $\begin{array}{l}\text { Electronic blackboard and } \\
\text { handheld devices }\end{array}$ & Stand alone \\
\hline CFS & $\begin{array}{l}\text { Online feedback (annotations to } \\
\text { presentations) }\end{array}$ & Notebooks & Stand alone \\
\hline ActiveClass & Feedback, Quizzes & PDAs & Stand alone \\
\hline
\end{tabular}

Table 1. Comparison of existing systems. 


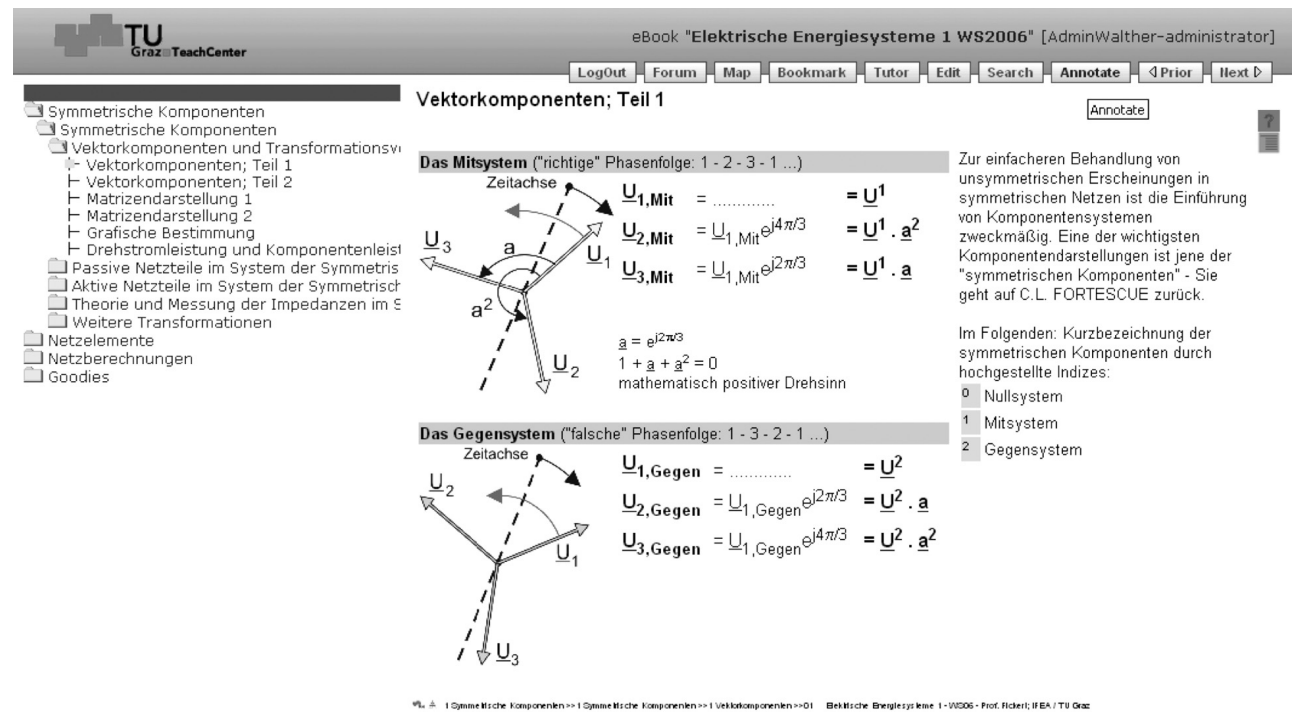

Figure 1. Typical eBook within the environment TUGTC.

intention of this feature was to support a complete eBook environment without focusing on communication and interaction processes.

The next step towards the interactive lecture was to create a presentation viewer for the lecturer with less difference to common PowerPoint presentations he/she is using for daily lecturing. By reducing all advanced features except forward and backward buttons, as well as a possibility to stop the presentation, it can be displayed online in the lecturing room, similar to other usual presentation techniques.

Furthermore, the interactivity between teachers and learners has been enhanced by implementing a so-called "Micro-blogging" functionality. Three possibilities for online live feedback or questions are offered to the students:

1. Simply by joining the same viewer as the one being used by the lecturer, the student can write a message via the web interface at the same time.

2. For mobile devices e.g. mobile phones, a special interface with respect to the limited interface size has been programmed. During lecturing, a specific URL is provided to allow writing text messages from mobile devices.

3. Finally, the possibility to write a simple email by offering an email address has also been established. Learners only need to define a predefined topic to distinguish between different interactive lectures.
To start the micro-blogging interactivity, the lecturer clicks on a small dot beside the other navigation element. The dot turns green - afterwards micro-blogging is running. If a student writes a message, the dot changes its color to an animated smiley, so the lecturer can easily recognize the interaction. Figure 2 shows the presentation slide and an open Micro-blog.

In the end, all taken measures are enumerated which should support interactive lecturing:

1. The usual learning management system has been used

2. The presentation should be done within the eBook functionality to benefit from all existing tools and communication possibilities there

3. A special kind of eBook Viewer has been created to reduce the eBook functionality to core presentation features.

4. A micro-blogging channel has been implemented to allow direct and live feedback from the auditorium.

5. A possibility to print the lecture slides within all annotations has been established.

\section{Experimental Setting - Proof of Concept}

The very first experiment including all described measures took place during the lecture "Social Aspects of Information Technology". This 


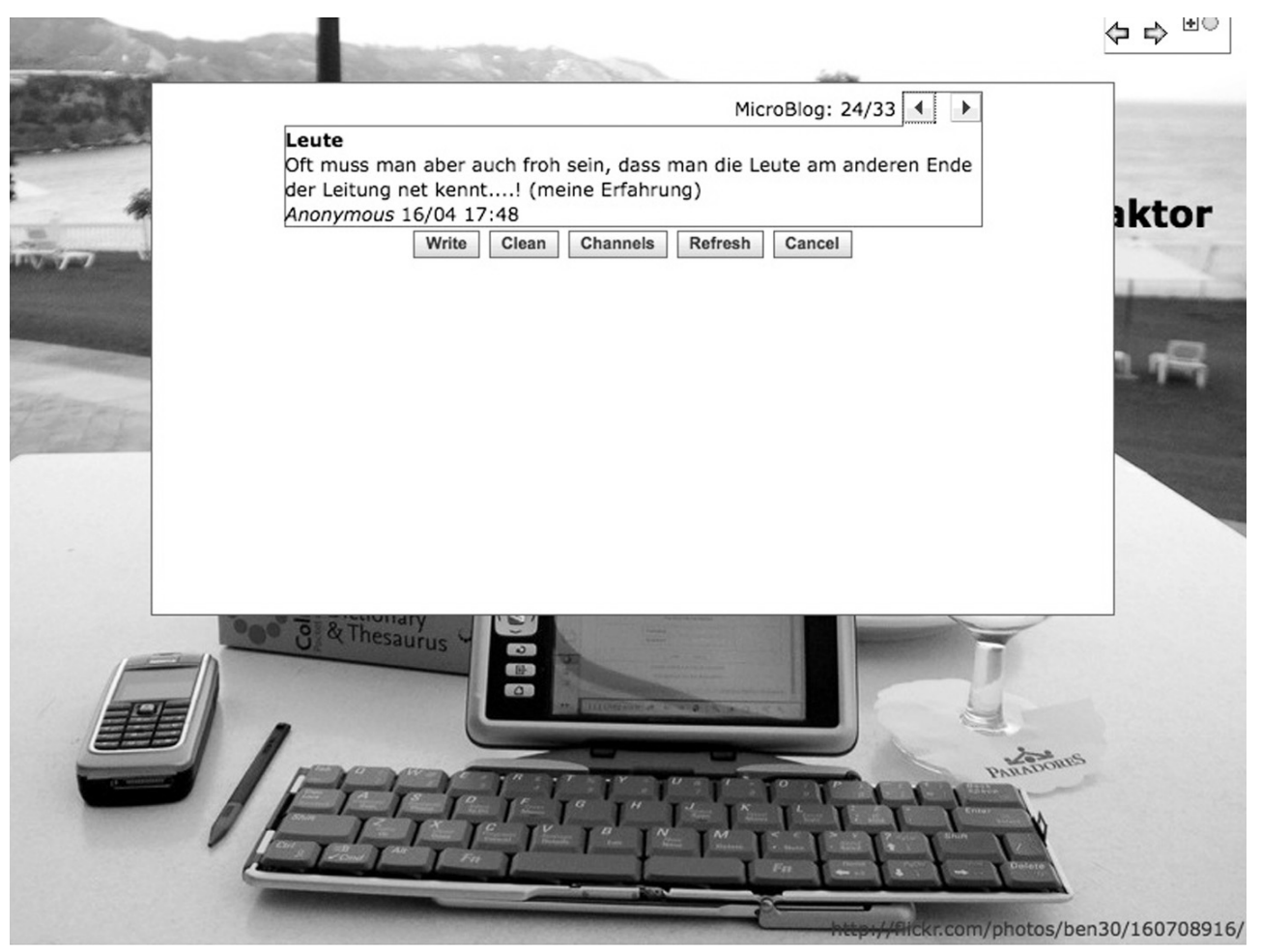

Figure 2. Typical Micro-blog annotation.

course is a compulsory one for BSc students of Electrical Engineering and Informatics and strives to develop a critical view on the way informatics influences modern society. Each year more than 200 students attend this course, following lectures on different topics like human computer interaction, eHealth, search engines, Weblogs as well as virtual worlds and informatics for different research fields.

Students should think about how information technology helps the society and learn to achieve a critical view on different approaches and services. Due to this fact, modern and innovative technologies such as Weblogs or Micro-blogs are used to observe and research their limits about advantages and disadvantages (Ebner \& Maurer, 2008b).

In two lecture units interactive lecturing was tested for the first time. First, students were encouraged to bring their devices with them and advised that Internet connection to the WLAN Hot spot in the lecturing room was running. A short introduction to the idea of interactive lecturing and providing the hyperlink for mobile access was followed by the presentation "Weblogs - at the dawning of the information age".

After the lectures, short oral interviews with some students took place, to get the first spontaneous impression of their thoughts:

Question: "Do you think interactive lectures have a potential for the future?"

Student 1: "Yes, indeed ... and I regret not taking my device with me, but I will next time"

Student 2: "I think it helps students overcome the barrier asking questions."

Student 3: "I appreciated this kind of lecture ... and used my laptop ... great application"

Student 4: "The lecture became much more interactive - I enjoyed asking questions and sharing opinions, furthermore I can use my own device - great"

\section{Results and Discussion}

The lecture lasted about 45 minutes - during this time approximately 40 devices were permanently connected to the Internet, which was counted via the WLAN Hot Spot by the network administrator (Figure 3). Thirty three Microblogs were sent by the learners with the help of the micro-blogging facility. Furthermore, 12 
annotations enhanced the existing slides with comments and useful links. About 20 students entered the chat room for discussion about the lecture topic.

It can be pointed out that there was much more interaction between lecturer-students and students-students compared to a usual lecture. From an overall technical point of view, the experiment can be stated as successful, but we have to look more in detail.

\subsection{Annotations}

The whole concept aimed to turn the static slides into an interactive and growing learning material, where students share and collaborate information and bring their experiences directly to the content pool. The lecturer explained the main ideas about adding short remarks - to enhance the presented slides with personal notes, useful statements, hyperlinks to other resources such as videos, pictures, articles etc. Due to the fact that all notes are not only added to the slides online, but also to the print version, the students' feedback was very positive. For future work it should be thought about the possibility to integrate other Web applications as, for example, del.icio.us by using the accordant API. So it would be possible to aggregate different resources and automatically display them within the environment or even add them to the print version.

\subsection{Micro-blogging}

Thirty three Micro-blogs during 45 minutes pointed out a high participation of the learners. The content of the contributions can be divided into short comments, longer statements and questions. The Micro-blogs were sent from mobile devices and laptops; no device was preferred. The huge number of contributions and the positive feedback of the students confirm that it was very easy to participate and send messages. The lecturer was very enthusiastic about this new form of feedback, but mentioned afterwards that is was very hard to follow each contribution just in time. The interruption of the presentation seems to be not as easy as expected beforehand. Because the Micro-blog contributions were displayed one by one, some students noticed that it would be more interesting if the Micro-blogs were displayed in a chronological order. Similar to twitter ${ }^{7}$, every learner can follow the stream and discuss without knowledge of the lecturer.

\subsection{Attention}

Due to the fact that different communication channels had been offered, students were very busy during the whole lecture. Based on video observation during the whole lecture and the

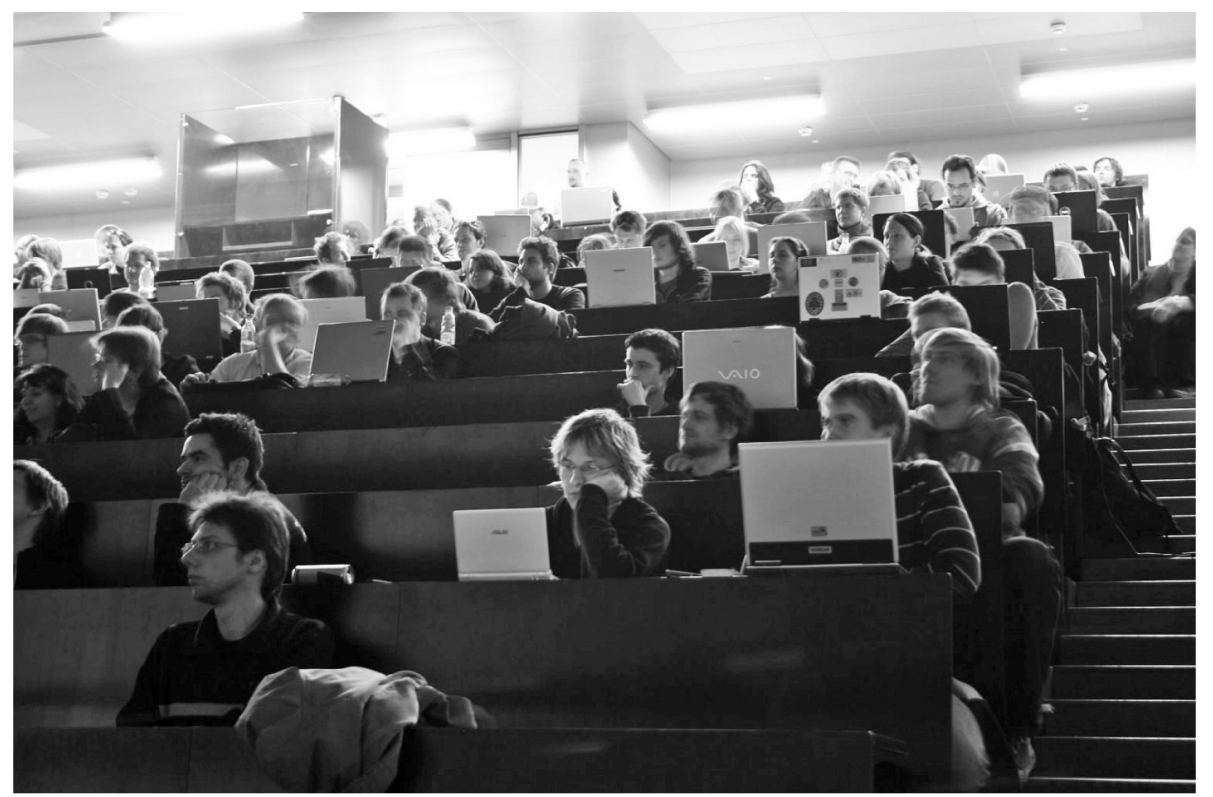

Figure 3. Picture of lecture room. 
analysis afterwards, it must be stated that students worked with the materials related to the content of the lecture and dealt with onlineslides on demand. This fact is of high importance because former studies showed that students are "working" on their laptops surfing the Internet, far from the context of the ongoing lecture. In other words, this kind of interactivity engaged students to work on the lecture content instead of being only physically present. On the other hand, it must be critically asked if this kind of engagement leads to poor attention as well. Further studies should clarify how learners are dealing with these possibilities and whether working with different channels simultaneously can become a future behavior in classroom or not. The main research question is how less attention paid to the lecture versus more engagement on the content changes the learning and teaching behavior. One interesting phenomenon can be observed: Each time a Micro-blog was opened by the lecturer, the attention rate of the learners raised considerably. The lecturer said that this seemed to be an appropriate methodology to focus students'attention back on the presentation.

\subsection{Feedback}

In general, all participants (lecturers and students) loved this new kind of lecturing. Students said that discussing during the lecture with colleagues was highly valuable in accomplishing their own thoughts. Both pointed out that they have to get familiar with the new possibilities offered and see where they benefit most. Furthermore no technical problems can be reported, only the lack of power sockets in the lecturing room leading to unintentional power offs of some devices.

\section{Conclusion}

Interactivity and active participation seems to lead to a new learning and teaching behavior. By using modern technologies, students'knowledge about new media and Web 2.0 new possibilities can be implemented even to large lecture rooms. Sharing and collaborating different pieces of content as well as communication over different channels allow rethinking didactical approaches. Both students and teachers reported a great potential for educating in big lecture rooms using new media. Including the possibilities of Web 2.0 in traditional learning behaviors leads to a big challenge. What must education of the future look like when anyone gets information just in time? The role of the lecturer will turn into a more facilitating one, as claimed for years.

The next steps in this research project will be improving the micro-blogging and annotation possibility. Furthermore, the concept of presentation must be rethought because it is still time consuming to prepare slides by using HTML. By developing a special kind of editor (Nagler et al, 2007), reusing of content as well as multiple adaptability should allow to remix and manage different resources. It can be imagined that instead of writing their own learning handouts, the teachers of tomorrow will be building a MashUp of learning objects, which can be commented or even remixed by learners to adapt it to their individual learning styles. These topics are of more technological than sociological and psychological nature. Future research must also address socio-motivational and psychological aspects of increasing interaction and engagement in traditional face-to-face lecturing. Following research work will address questions like how this kind of interaction will work for a long term and in other disciplines that are not close to the subject of informatics?

Finally, it must be concluded that although interactive lecturing is a promise for the future of education, it is necessary to consider that complete new didactical approaches and teaching challenges have to be evolved by teachers. The aim of technology-enhanced learning must ensure that learners become more engaged and that learning proceeds through and by conversations.

\section{Acknowledgments}

We would like to express our gratitude to the people who helped us to implement the didactical scenario of interactive lecturing, assisted with all other necessities for the successful adoption during the lectures. Firstly, we sincerely thank Prof. Nicolai Scerbakov and his team for the programming and adoption of WBT-Master and his almost endless patience 
during the development phase. Very special thanks go to Walther Nagler for helping us to establish the presentation as eBook and taking a lot of pictures during the lecture. We are equally indebted to Christian Stickel for filming during the lecture and creating a short YouTube Video (http: //www . youtube. com/watch?v= AEozd5TJGi8). Last but not least, thanks to all other unnamed people who supported this work before, during and after the project.

\section{References}

[1] Anderson, R. J., Anderson, R., VAndegrift, T., Wolfman, S., YASUHARA, K., Promoting Interaction in Large Classes with Computer-mediated Feedback. In: Designing for Change in Networked Learning Environments, Proceedings of CSCL 2003, Bergen, pp. 119-123, 2003.

[2] Augar, N., Raitman, R., \& ZhOU, W., Teaching and learning online with wikis. In: Atkinson, R., McBeath, C., Jonas-Dwyer, D., \& Phillips, R. (Eds.), Beyond the comfort zone: Proceedings of the 21st ASCILITE Conference, (pp. 95-104), December 5-8, Perth, Australia, 2004.

[3] BERNER-LEE, T., Information management: A proposal, 1989. http://www.w3.org/History/ 1989/proposal . html (last visited: July 2008).

[4] BLIGH, D. A., What's the Use of Lecturing? Devon, England: Teaching Service Centre, University of Exeter, 1971.

[5] CADDICK, S., Wiki and other ways to share learning online. Nature, 442, 7104, 744-744, 2006.

[6] Conte, R., PAOLuCCI, M., Intelligent social learning. Jass-the Journal of Artificial Societies and Social Simulation, 4 (1) (2001) U61-U82.

[7] Datta, A., OTtmanN, T. Towards a Virtual University. Journal of Universal Computer Science 7, p. 870-885, 2001.

[8] Dietinger T., Maurer H., GENTLE - General Network Training and Learning Environment. Proc. of ED-MEDIA98/ED-TELECOM98, p. 274-280, Freiburg, Germany, 1998.

[9] Downes, S., e-Learning 2.0. ACM e-Learn Magazine, October 2005 (10).

[10] EBNER, M., E-Learning $2.0=$ e-Learning $1.0+$ Web 2.0? Second International Conference on Availabilty, Reliability and Security, ARES, IEEE, p. 1235-1239, (2007b).

[11] Ebner, M, Holzinger, A., Maurer, H., Web 2.0 Technology: Future Interfaces for Technology Enhanced Learning?, Stephanidis, C. ed. Universal Access to Applications and Services, Lecture Notes in Computer Sciences (LNCS 4556), Springer, Heidelberg, Berlin, New York, p. 559-568, (2007b).
[12] Ebner, M, Schiefner, M., Mircoblogging - more than fun? In Proceedings of IADIS Mobile Learning Conference 2008, Inmaculada Arnedillo Sanchez and Pedro Isaias ed., Portugal, 2008, p. 155-159, (2008a).

[13] Ebner, M., Maurer, H., Can Microblogs and Weblogs change traditional scientific writing? In Proceedings of E-Learn Conference, AACE, accepted, in print, (2008b).

[14] Ebner, M., TARAghi, B., A Blog Sphere for Higher Education. Proceedings of the 20th World Conference on Educational Multimedia, Hypermedia and Telecommunications (ED-Media), p. 5618-562, (2008c).

[15] Ebner, M, SchiEfner, M., Microblogging - more than fun? In Proceedings of IADIS Mobile Learning Conference 2008, Inmaculada Arnedillo Sánchez and Pedro Isaías ed., Portugal, p. 155-159, (2008d).

[16] Evans, C., The effectiveness of m-Learning in the form of podcast revision lectures in higher education. Computers \& Education, Volume 50, Issue 2, February 2008, p. 491-498, 2007.

[17] Farmer, J., Bartlett-BragG, A., Blogs anywhere: High fidelity online communication. Proceedings of ASCILITE 2005: Balance, Fidelity, Mobility: maintaining the momentum?, pp. 197203, 2005.

[18] Gleason, M., Better communication in large courses. College Teaching, 34 (1), p. 20-24, 1986.

[19] Helic, D., Maurer, H., Scerbakov, N., Knowledge Transfer Processes in a Modern WBT System. In: Journal of Network and Computer Applications, Vol. 27, Issue 3, p. 163-190, 2004.

[20] Holzinger, A., KickMeier-Rust, M., Albert, D., Dynamic Media in Computer Science Education; Content Complexity and Learning Performance: Is Less More? Educational Technology \& Society 11, 1, 279-290, 2008, (ISSN 1176-3647).

[21] Huber, T., Nagler, W., Ebner, M., The ABCeBook System: From Content Management Application to Mash-up Landscape. Proceedings of the 20th World Conference on Educational Multimedia, Hypermedia and Telecommunications (ED-Media), p. 6015-6022, 2008.

[22] Huberman, B. A., Romero, D. M.. Fang, W., Social networks that matter: Twitter under the microscope, FM, Volume 14, Number 1-5, 2009. http://www.uic.edu/htbin/cgiwrap/bin/ ojs/index.php/fm/article/view/2317/2063 (last visited January 2009).

[23] Java, A., Finin, T., Song, X., Tseng, B., Why we Twitter: Understanding Microblogging Usage and Communities. Proceedings of the Joint $9^{\text {th }}$ WEBKDD and $1^{\text {st }}$ SNA-KDD Workshop 2007.

[24] Karger, D. R., QUAN, D., What would it mean to blog on the semantic web? Web Semantics: Science, Services and Agents on the World Wide Web 3, pp. $147[-157,2005$. 
[25] Korica, P., Maurer, H., Schinagl, W., The growing importance of e-Communities on the Web. International Conference of e-Communities on the Web, International Conference on Web Based Communities (IADIS), p. 165-174, 2006.

[26] Kulathurmamaiyer, N., Maurer, H., Current Developments of Mashups in Shaping Web Applications. Proc. of ED-Media 2007, AACE, USA, p. 1172-1177, 2007.

[27] LuCA, J., MCLoughlin, C., Can blogs promote fair and equitable teamwork? Proceedings of ASCILITE 2005: Balance, Fidelity, Mobility: maintaining the momentum?, pp. 379-385, 2005.

[28] MaUrer, H., Schinagl, W., Wikis and other eCommunities are changing the Web. Proceeding of ED-Media 2006, AACE, p. 2858-2866, 2006.

[29] McFedrIES, P., All A-Twitter. IEEE Spectrum, 84, October 2007.

[30] Motschnig-Pitrik, R., Holzinger, A., Studentcentered Teaching Meets New Media: Concept and Case Study. IEEE Journal of Education Technology \& Society 5(4), p. 160-172, 2002.

[31] Nagler, W., Ebner, M., Scerbakov, N., Flexible teaching with structured micro-content - How to structure content for sustainable multiple usage with recombinable character. Proceedings of International Conference on Interactive Computer Aided Learning, Villach, Austria, 2007.

[32] NIELSEN, J., Introduction to Usability, Jakob Nielsen's Alertbox, Usability 101. http: //www. useit.com/alertbox/20030825 .html (last visited July 2008), 2003.

[33] OpASChOWSKI, H. W., Generation Die Medienrevolution entlässt Ihre Kinder: Leben im Informationszeitalter. Hamburg/Ostfilden: Kurt Mair Verlag, 1999.

[34] O'ReILly, T., What is Web 2.0 - Desing Patterns and Business Models for the Next Generation Software, 2005. http: //oreilly.com/pub/ a/oreilly/tim/news/2005/09/30/what-isweb-20.html (last visited: July 2008)

[35] PeschKe, R., Lübecke, M (2005), Can blogs promote fair and equitable teamwork?. Proceedings of ASCILITE 2005: Balance, Fidelity, Mobility: maintaing the momentum?, pp. 379-385.

[36] Preece, J., Sharp, H., Rogers, Y., Interaction Design: Beyond Human-Computer Interaction. Wiley, New York, 2002.

[37] Prensky, M., Digital natives, Digital Immigrants, On the Horizon, 9 (5), p. 1-6, 2001.

[38] Purgarthofer, P., Reinthaler, W., Exploring the "Massive Multiplayer E-Learning" Concept. Proceedings of $20^{\text {th }}$ ED-Media Conference, AACE, p. 2015-2023, 2008.
[39] Raitman, R., Augar, N., \& Zhou, W., Employing Wikis for Online Collaboration in the E-Learning Environment: Case Study. In Proceedings of the Third International Conference on Information Technology and Applications, (pp. 142-146), IEEE Computer Society, July 04-07, Sydney, Australia, 2005.

[40] Ratto, M., Shapiro, R. B., Truong, T. M., GrisWORLD, W. G., The ActiveClass project: Experiments in encouraging classroom participation. In: Computer Support for Collaborative Learning, 2003.

[41] Richardson, W., Wikis, Podcasts and Other Powerful Web Tools for Classrooms. Corwin Press, Thousands Oaks (CA), 2006.

[42] Schaffert, S., Hilzensauer, W., On the way towards Personal Learning Environments: Seven crucial aspects. In: elearningpapers 9, July 2008. http://www . elearningpapers .eu/index . php?page $=$ doc\&doc $\_$id $=11938 \& d o c l n g=6$ (last visited July 2008)

[43] Scheele, N., Wessels, A., Effelsberg, W., HOFER, M., FrIES, S., Experiences with interactive lectures: considerations from the perspective of educational psychology and computer science. In Proceedings of 2005 Conference on Computer Support For Collaborative Learning: Learning 2005: the Next 10 Years! (Taipei, Taiwan, May 30 June 04, 2005), Computer Support for Collaborative Learning, International Society of the Learning Sciences, p. 547-556, 2005.

[44] SChIEFner, M., EBnER, M., "Weblogs, more than just a toy?" or "Should I keep an e-Portfolio for my PhD study?" In: Interactive Computer Aided Learning, ICL 2008, Villach, 2008.

[45] Schmidt, J., Schönberger, K., Stegbauer, C., Erkundungen von Weblogs - Anmerkungen zum Stand der Forschung, kommunikationgesellschaft 6, 4, pp. 1-20, 2005.

[46] Smith, B., Just give us the right answer. In: $H$. Edwards, B. Smith \& G. Webbs (Ed), Lecturing. Case studies, experience and practice, London, p. $123-129,2001$.

[47] TAPSCOTT, D., Growing up digital: The Rise of the Net Generation. McGrwaHill: New York, 1997.

[48] Towned, N., Podcasting in Higher Education, Media Onlinefocus 22. British Universities Film \& Video Council, 2005. http://www.bufvc.ac.uk/publications/ mediaonlineissues/moF22_vf61.pdf (last visited: July 2008)

[49] Walker, J., Weblog, Definition for the Routledge Encyclopedia of Narrative Theory, 2007. http://jilltxt.net/archives/blogtheorising/final_version_of_weblog_ defintion.html (last visited July 2008)

[50] WEISER, M., The Computer of the twenty-first century, Scientific American. 265 (3), p. 94-104, 1991. 


\section{Hyperlinks}

[1] Eurostat: Internet Access within European Union http: //epp.eurostat.ec.europa.eu/portal /page?_pageid=1996, 45323734\&_dad=portal\& _schema=PORTAL\&screen=wel comeref\&open=/ isoc/isoc_ci/isoc_ci_in\&language $=$ de\& product=EU_MASTER_information_society\& root=EU_MASTER_information_society\& scrollto $=0$ (last visited July 2008)

[2] Statistics Austria: http://www.statistik. atsociety//web_en/statistics/ information_ict_usage_in_households/ 028945.html (last visited July 2008)

[3] http://www.mpfs.de/fileadmin/JIM-pdf07 /JIM-Studie2007.pdf (last visited July 2008)

[4] http://www . bedu.com/ (last visited July 2008)

[5] http://classinhand.wfu.edu/ (last visited July 2008)

[6] http://www.ipsi.fraunhofer.de/concert/ index_en.shtml?projects/past_projects/ studeo (last visited July 2008)

[7] http: //twitter. com (last visited July 2008)
Received: November, 2008 Revised: February, 2009 Accepted: February, 2009

\section{Contact address:}

Martin Ebner Social Learning / Computer and Information Services Graz University of Technology Rechbauerstrasse 12, Graz A-8010, Austria e-mail: martin.ebner@tugraz . at

MARTIN EBNER is currently head of the Department for Social Learning of Computer and Information Services at Graz University of Technology. He is responsible for all e-Learning activities of the University. His research focuses strongly on the use of Web 2.0 for teaching and learning purposes. Martin has delivered a number of lectures and seminars around the topic of e-Learning and the use of computers in educational settings. He studied civil engineering from 1995-2000 and got his M.Sc. from the Institute of Structural Concrete. Afterwards, Martin worked as a scientific assistant at the Institute of Structural Concrete and wrote his $\mathrm{Ph} . \mathrm{D}$. thesis about e-Learning in structural engineering. Since 2005 he holds a Ph.D. in technical sciences from Graz University of Technology. From 2005 to 2006 he worked at the Institute for Building Informatics as Assistant Professor. Since September 2006 Martin is head of the Department for Social Learning of Computer and Information Services. He wrote not only an amount of international publications and gave a number of presentations about e-Learning, but is also member of various national and international research groups and scientific boards. Martin is one of the biggest EduBloggers in the German speaking area and conducts the e-Learning Blog (http://elearningblog.tugraz.at). 
